\title{
CRaSh-ing into HCI
}

\author{
Janet C Read, Matthew Horton, Gavin Sim and Emanuela Mazzone \\ School of Computing, Engineering and Physical Sciences, \\ University of Central Lancashire, \\ Preston, PR1 2HE, England \\ \{jcread, mplhorton, grsim, emazzone\}@uclan.ac.uk \\ WWW home page: http://www.uclan.ac.uk
}

\begin{abstract}
This paper describes a novel classroom based project that looked at methods for sharing the contributions of students during activities in undergraduate classes. Initially intended for HCI students, the CRaSh product has wide applicability for creative use of class time and for inspiring students in their design work. The method employed was a prototype interface that allowed the sharing of digitally ink based content by uploading this content to a secure website. Encouraging shared learning, the project focuses on the creation, completion and management of worksheets for students. This paper describes the design of the prototype and explores the ethical and legal discussions associated with this sort of product.
\end{abstract}

\section{Introduction}

This paper describes a product that was designed to provide undergraduate students on an introductory Human Computer Interaction (HCI) course an opportunity for a new learning experience. The project was intended to increase student engagement, assist in student learning and promote lecturer reflection. As uptake in British Universities has increased, the education of a more diverse set of learners and the challenges of larger class sizes and wider participation has provoked many innovative and interesting solutions. Proposing a new solution requires imagination and enthusiasm but the evaluation of new solutions is altogether a more complex process.

We describe here the design and implementation of CRaSh and conclude with a discussion of the difficulties surrounding the evaluation of its use in context. 


\subsection{Costs and benefits of Technological Interventions in the Classroom}

In the modern university, there are several challenges to overcome. Some of these, like teaching large groups of students from different backgrounds, are generic across all courses; others are specific to a single subject area. In HCI Education, there are several challenges, three of these are:

- The teaching of design.

- Combining theory and practice.

- Teaching skills that are useful in industry.

Often feeling rather marginalized in a computer science curriculum, the HCI lecturer seeks to encourage reflection rather than skills gathering, design rather than development, and theory rather than fact. This makes HCI relatively difficult to teach and the engagement of students can be quite low, partly as they see $\mathrm{HCI}$ as a 'wooly' or 'soft' choice, but also as they do not fully understand the different emphasis placed by the typical HCI lecturer.

Disseminated through the HCI Educators workshop and via other similar routes, there have been many novel ideas suggested to improve the overall student experience in the HCI classroom. These novel ideas include industry led assessment and socially responsible project work [12], participation in real research studies, peer teaching [8], readings based teaching and case studies [5]. These approaches all have merits; and in all cases, a higher level of student engagement is reported.

One of the downsides to educational initiatives is the overhead on the course tutor in the management of the novel methods. In recent years, the increase in uptake of content management systems, the need to comply with disability legislation, and the demands of a computer-centered student base have all increased the workload on lecturers and course managers. It is certainly the case that as learning and teaching becomes more individualized and less lecture room driven, the cost to the instructor is higher. One metric to be considered in technological solutions is the cost to the course manager / lecturer. It would be expected that there would be a cost at the outset in developing the application but additionally, the tutor should be able to see some payback with the product use over time.

Technological solutions for education are often seen as a 'quick fix'. In primary and secondary state education, certainly in the UK, technology is encouraged as a means to enhance student learning and increase motivation, although the extent to which this succeeds is heavily debated. Computers in the classroom, broadband access to the internet, and devices such as interactive whiteboards can be found within the majority of classrooms today but rigorous studies that examine the real value of these products are few and far between.

There are several accounts of technology enhanced learning in Higher Education and Further Education. These include the use of tablet PCs in lectures [7], the use of lecture room response systems [4], and interactive lectures using mobile systems [11]. In most of these studies, the emphasis is on the development of a novel solution; the costs ad benefits are less readily reported.

The focus on technology in HE has been on the lecture room. This is not surprising as the lecture room is a difficult place for student participation (hence ideas like tablet PCs in class), is also a place where student engagement is low (hence the ideas for interactive systems) and is a place where the lecturer is not able 
to easily gauge the learning experiences of the students (hence the lecture room response systems). Enhancing small group activities with technology is much less reported, however the small group space lends itself to different technological enhancements. In particular, due to the smaller potential numbers of users, more expensive, and therefore scarcer technologies can be employed.

This paper describes such a technological innovation. The CRaSh application depends on a small (circa 5) number of tablet PCs and a web server. CRaSh is intended for use in small groups of around 20 students, to support small group work.

This paper begins with a discussion of the background pedagogy and then goes on to describe the prototype application before concluding with some observations about the potential for the product and a discussion about the evaluation of technological solutions in the classroom.

\subsection{Creating and Sharing in the Classroom}

There are several pilot projects using tablet PCs in the classroom being carried out across several institutions. These include Notre Dame, MIT, and the University of Washington and the focus in these studies is to examine the impact of these devices as teaching tools [7], however the take up of use of tablet PCs in educational settings has not been as rapid as was earlier hoped. One reason for this is that the applications that support educational work are not present and a second is the cost of the technology. The cost of a tablet PC is far greater than that of a laptop with similar technical specifications. That said, several studies point to the positive aspects that tablet technology brings to learning situations, especially with regard to improved visibility and the possibilities for sharing the work so created [6], [14].

As an adjunct to a classroom experience, a computer; tablet or otherwise, offers a unique ability to save work that can be referenced, or referred back to, at a later date. This has been seen as a benefit by students involved in such studies [7], aligned with this, students report that the quality of lecturers notes, and the ability to create notes of their own before a class improves when computers are brought into the learning space as this allows students to spend more time listening to the lecturer [1], [7].

When technology can be connected, either to other pieces of technology, or to other output / input devices, one way in which the addition of technology into the lecture space affects learning is in the increased possibilities for interactivity between the students and also with the tutor. Several studies have shown that the use of interactivity in lectures increases engagement and motivation [9],[10]. The suggestion is that knowing work might be shared or seen by others, or knowing that it is possible to make instant responses to a lecture, encourages a level of thought and reflection above the superfluous. Aligned with this idea, one way to engage students is to let them see the work they have just completed or see the work of others within their class. It is commonly the case in early education to show ones work to the class or to read a story that has been created but, as the learners become older, this practise is much less adopted.

Several low-tech solutions exist for sharing work; one is to have the students write on overhead projector films and then present these to the class, another is to use a visualiser to directly display their written work. The problems with these 
methods are that after the 'show and tell' moment, the work cannot be back referenced and the time taken to show multiple answers can be excessive. An extra problem can occur when students might feel embarrassed about showing their work and would prefer to remain anonymous.

\subsection{Context of the Work}

The work described here was developed at the University of Central Lancashire (UCLAN) where HCI is taught as an introductory course to around 120 students each year. HCI is taught in the second year with approximately $75 \%$ of the participating students having completed a web design course in year one that introduced some introductory HCI principles.

Students on the introductory HCI course come from a wide variety of degree streams including Computer Forensics, Games, Web and Multimedia, Database Systems, Networks and Combined Honours.

The second year HCI course is based on the [3] text book and is taught in 24 1hour lecture classes over a full academic year. The students also attend tutorials and a handful of practical sessions; tutorials and practical sessions are typically held in groups of around 20 students at a time. Generally, but not always, the tutorials are taken by $\mathrm{PhD}$ students or associate staff who do not deliver the core syllabus. In general, the process is that the course leader prepares an outline activity for the tutorial class, emails this out to the tutors and then goes on to prepare the next weeks work. Apart from some informal reporting back, there is currently no system in place to ensure that the tutorial classes achieved their aims

Assessment on the course is partially dictated by local regulations that stipulate that a certain percentage of the marks have to be gained from a formal examination. In addition, a department policy on limited groupwork dictates that coursework, where used, be primarily individual. This restricts the options for innovative assessment methods. In 2006/7, the assessment pattern was $50 \%$ exam, $40 \%$ a single coursework assignment and $10 \%$ practical activities.

\section{CRaSh - CReate and Share}

CRaSh is a prototype application that allows students to create and share notes that they create on a tablet PC. There are two similar solutions found in the literature, the first is described in [13]. This application has two interfaces, the student interface and the presenter interface, and the students respond at points, using their interface, during class teaching. The application allows the responses to be saved, thus allowing discussions about the student learning during and after the class. That said, the application focuses on interaction rather than on note taking and is designed to promote a two way dialogue, during classes, between the tutor and the students. NotePals [2] is a more similar solution. This application uses digital ink and allows the sharing of notes made on PDAs. All three of theses applications, NotePals, CRaSh and the [13] application, use two interfaces, one for the student and one for 
the tutor. In NotePals and CRaSh, the former is primarily designed for note taking, the latter for browsing.

In NotePals, a custom interface was created for the PDAs to make the best use of the small space on the screen, in CRaSh, customisation was provided via a tablet driven interface that, aside from the navigation buttons, allowed a large and useful writing space. The interface for the note taking aspect of CraSh can be seen in Fig. 1.

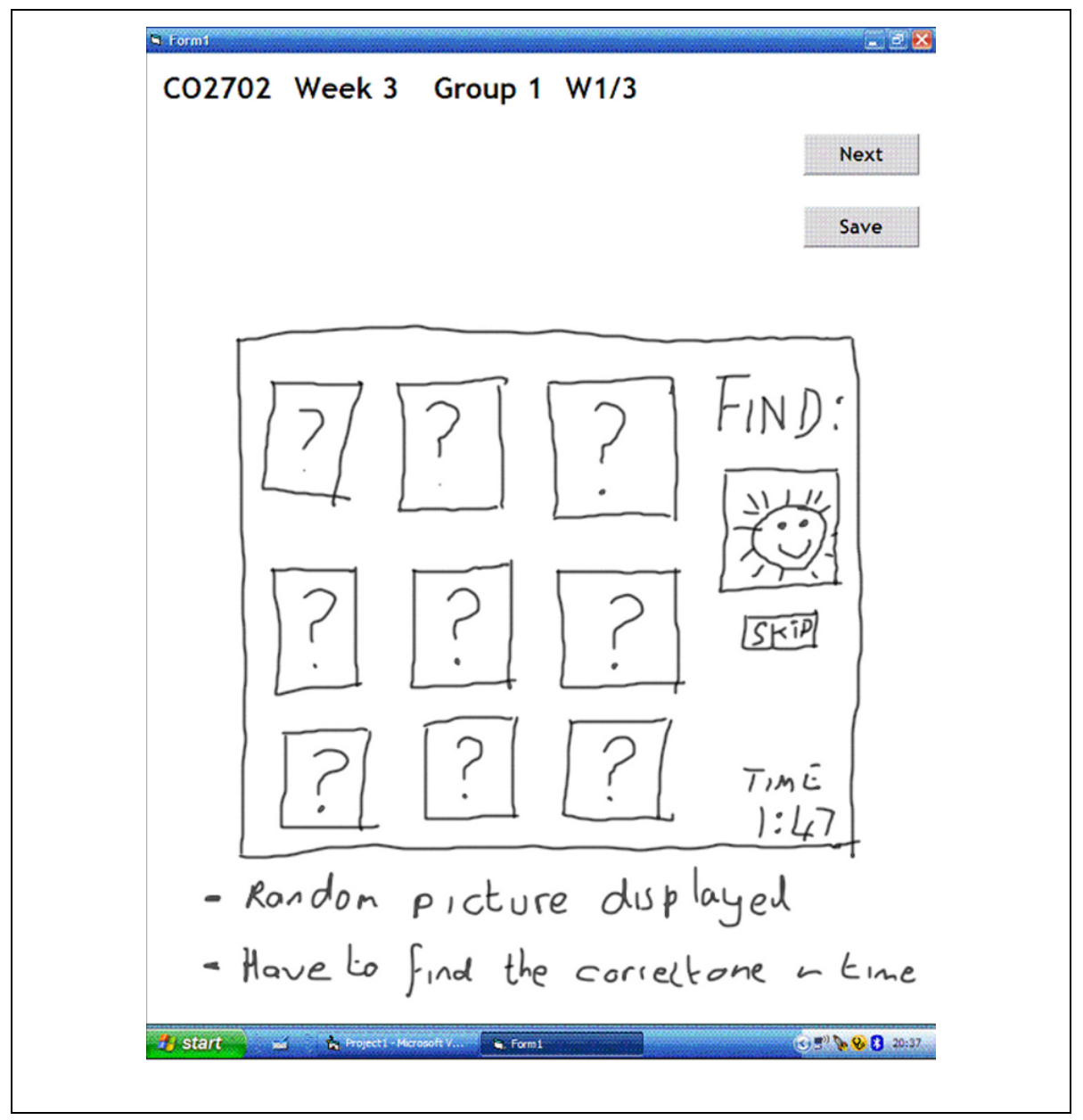

Fig 1. The CRaSh Note Taking Interface

As well as providing an interface for free sketching and note making, the CRaSh prototype application has an added feature by which lecturers and instructors can design worksheets ahead of time and send them to the students for completion in class. This feature makes this application different from NotePals; this is not a criticism of NotePals as the size limitations of the NotePals interface would render such an application nonsensical. 
Worksheets in CRaSh are saved as pictures (in pdf format) on the tablet PCs and then sent across to the server using any available wireless networks. An option, if the wireless network is not available, is to use physical communication methods like USB memory sticks to transfer the files from the tablet PCs to a computer that is physically connected to the internet. Once the pictures from the worksheets are in the host computer, they can be uploaded to the server. It is also possible to upload directly from the tablet $\mathrm{PC}$.

The second interface for CRaSh is the web interface where students log on to see the worksheets that have been created and also to download worksheets for the next class if they have not already received them. This interface involves the use of a Postgress database to store data including student details, course and group details, and uses the server side scripting language PHP in the manipulation of this data. This interface is shown in Fig. 2.

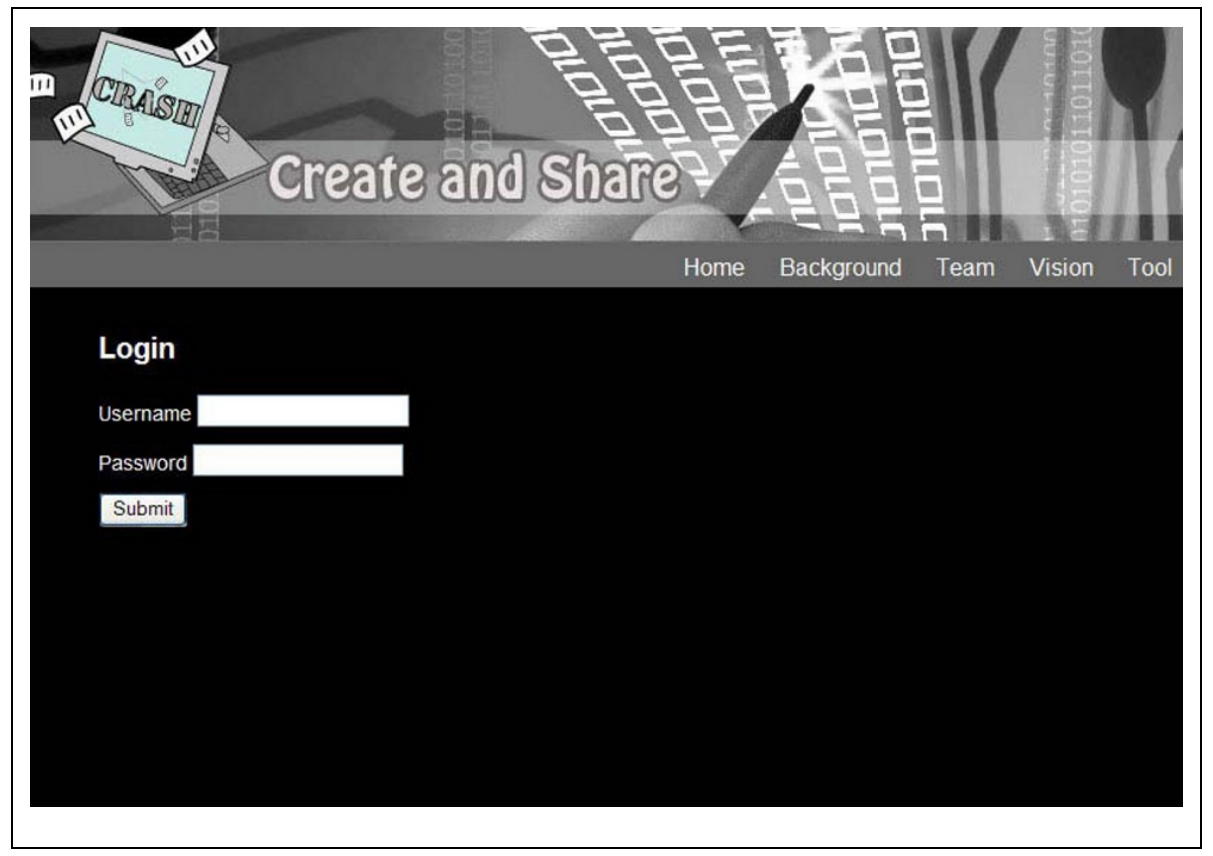

Fig 2. The CRaSh Login Interface

In the default option, work that is uploaded to the CRaSh website becomes visible to all others in the group. The group is defined by the lecturer and so, whereas individuals could be defined as groups and thus, a student could only see his or her own work, the normal situation is that a group will comprise as a minimum the members of the tutorial class, or maximally, all the students enrolled on the course. The lecturer (as administrator of the application) can change viewing privileges for modules (courses) that he / she manages by setting up these course groups within the admin section of the web interface. It is not possible for students to hide their work so the system is very open; when the work is viewed, it is anonymous and so, unless 
they know one another's writing style, students work remains anonymous with only the students who have created the piece of work knowing which is their own.

The CRaSh administrator has the option within the web interface to create new modules, add new staff members, add new students, and also add students to modules. This allows different lecturers to use the application with other modules if they wish and also to share the application with other members of staff who may also be teaching on the same module or who may have seen the application and wish to make use of it within another discipline.

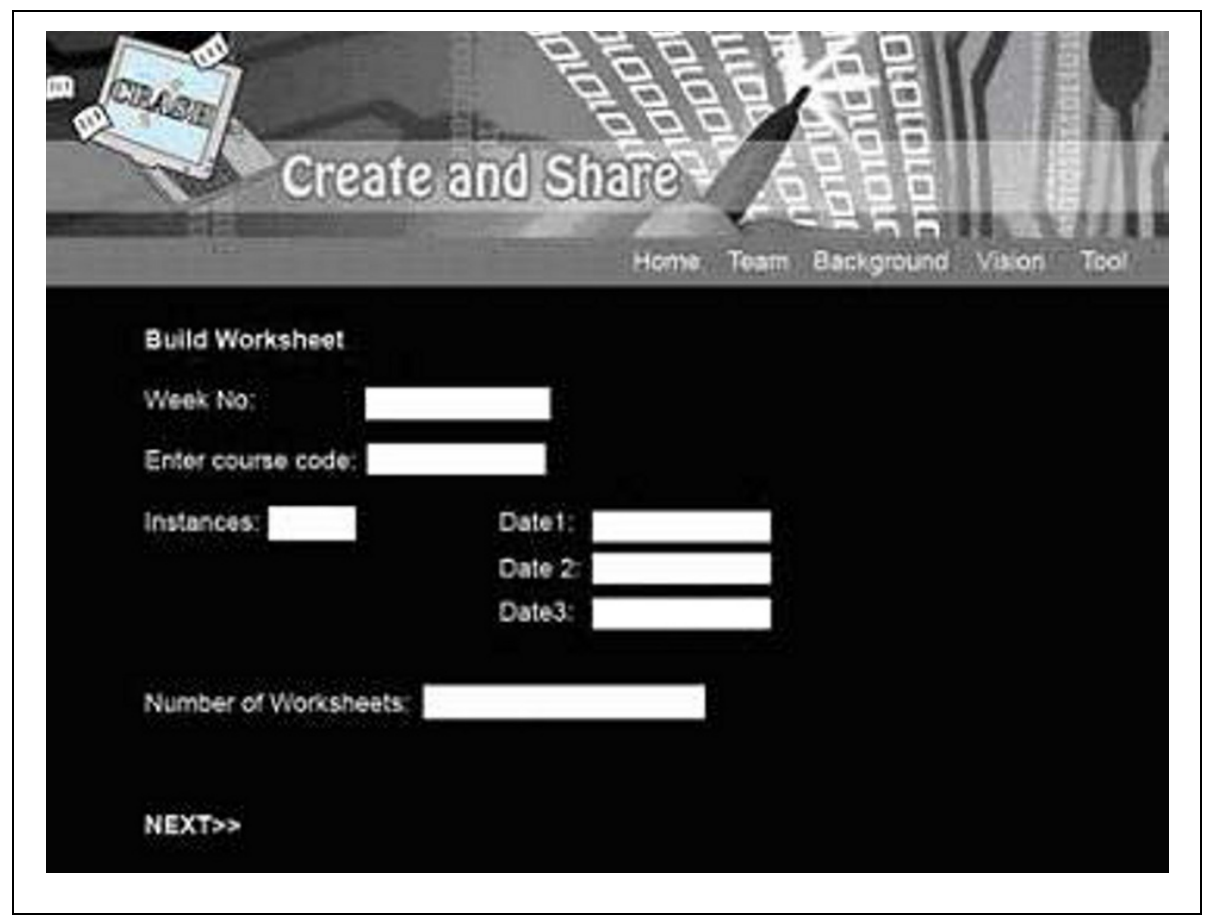

Fig 3. The CRaSh Create Worksheet Page

The current application is push technology in that it is the instructor who creates the worksheets at the standard PC and sends them to the students via email (or leaves them on the server to be downloaded by the students themselves). These worksheets are then uploaded to the tablet PCs by the students at the beginning of the class. This does therefore restrict the students on the tablet PCs in that they can only complete as many sheets for an individual class that they have been given. Thus, in the example shown in Fig. 1, the students know that there are only three worksheets available to them. This limitation was built in as it encourages sensible use of the tablet interface and ensures that the system does not become overloaded. Without such constraints, students have been known to cover 8 or 10 tablet pages with scribbled notes in a class session. 
It is during the creation of worksheets that the necessary file organisation for the web material is created. The instructor needs to specify courses, weeks, and groups. The current application only allows a maximum of ten groups for each course/week but this would be reasonably easy to alter within the database on the server. There is also a current limit on the number of worksheets per course/week to three. The worksheet creation screen is shown in Fig. 3.

When worksheets are uploaded, the metadata, course, group, worksheet number is sent to the server and used along with the image to ensure that the image is stored in the correct place on the server. By sending the extra data with the image it ensures that the worksheets are only viewed by the students who are registered on the specific course relating to the uploaded image.

\subsection{Usability of CRaSh}

The CRaSh application was user tested in June 2007 with four students from the second year undergraduate HCI class. The application was found to be very easy to use and each part of the system worked without any problems. However, there were several requests from the students:

1. Students wanted the option of working in a landscape format.

2. Students wanted to be able to save (and upload) the worksheet even when they had only done one from a set of three.

3. Students wanted to be able to select pen colour from a palette.

4. Students wanted a space on the web server application to add comments to the images.

The first three of these requests have since been incorporated; the last one has not yet been implemented as there are several questions about the security and privacy aspects of this add-on that have yet to be resolved.

Two members of staff user tested the application, both had no difficulty creating worksheets and driving the application (a small instructional video was made to assist in this) but each commented on the limitations of the templates for worksheets. This limitation was noted and considered to be worth pursuing at a later date. One useful idea was to have small thumbnails of the different worksheet types available so the first time user was better able to know what to create. This has been added.

\subsection{Evaluation of CRaSh}

The CRaSh team was keen to test out the application with a cohort of students in real use. There are several difficulties with evaluating technology interventions and because of this a filed evaluation has not yet been completed. Initially, the intention was to have all the students in the undergraduate HCI class use the technology for six weeks, with half using it for the first six weeks, and the rest for the following six weeks. However, this was not possible as there were concerns about the accessibility of the technology for students with various learning difficulties and sensory disabilities. Because, in its present form, the application could not be made inclusive, a formal trial of it was not possible. 
The authors are adapting the application so it can be used with a first year entertainment computing module in the summer of 2008. This module is less problematic as it currently has no students with sensory disabilities and, as it is a module that students have only to pass, that is, the marks accrued don't matter, an intervention study, as is needed in this case, is easier to carry out.

In a HCI classroom, it seems that CRaSh is most effective for small group work activities. In these instances, a group of two or three students would share a tablet PC whilst collaborating on a single well defined problem. The students would sketch and note their ideas on the tablet PC and later, would all be able to access the single notes and images as well as visit the offerings of their peers which would allow them an opportunity to reflect on their own work and compare their ideas with others.

\section{Summary}

The paper has described the CRaSh application and reflected on its use. The application provides lecturers with a facility to create worksheets that can be used very easily and has the added benefit of saving time and resources in producing paper worksheets for every student. The application also allows the lecturers to view the work that has been created providing them with a chance to see whether students have understood the subject matter taught and the questions that they have been asked.

CRaSh allows students to share their work with other members of their class. This also gives the students a chance to see whether they understood the work in the same way other members of the class did or where they may need to improve their skills at communicating information or their subject knowledge. This self discovery of learning is known to be especially useful for learners. The anonymity ensures that students do not feel threatened or identified.

With the tool being web based, the work can be viewed as soon as it is uploaded and by anyone from the class that is logged on at the time, there is no restriction to that amount of people who can view the work simultaneously. This allows for the material to be reviewed at the same time in class but also from home or from labs on normal PCs at a later date. As all the work sheets are saved, there is a useful resource created that can be reviewed at the end of the year to determine patterns of engagement and student activity. This allows staff to make changes to their teaching either by changing the way they teach a particular area due to pattern emerging showing students did not understand what they were being taught, or where they feel further work is required in certain areas of the syllabus. It also allows for a great revision guide for the students who have access to all the group work that has been done throughout the year, not only by themselves but also others for comparison and better understanding.

One attractive extension of the tool is to incorporate other digital ink technologies including digital pens and PDAs so the application is not so dependent on the tablet PCs, the web based side of the application would need little or no modification to achieve this. 
Further evaluations of the tool will be carried out by students and staff to show the benefits the tool has brought to the groups that have used it.

\section{Acknowledgments}

We would like to acknowledge Microsoft and the ICS subject centre of the HE Academy that provided funding for this project.

\section{References}

1. Berque, D., et al., The design of an interface for student note annotation in a networked electronic classroom. Journal of Network and Computer Applications, 2000. 23: p. 77 91.

1. Davis, R., et al. NotePals: Lightweight note sharing by the group, for the group. in CHI '99. 1999. Pittsburgh: ACM Press.

2. Dix, A., et al., Human-Computer Interaction. 3rd ed. 2004, Harlow: Pearson.

2. Draper, S.W. and M.I. Brown, Increasing interactivity in lectures using an electronic voting system. Journal of Computer Assisted Learning, 2004. 20(1): p. 81 - 94.

3. McCrickard, D.S., C.M. Chewar, and J. Somerwell. Design, Science, and Engineering Topics? Teaching HCI with a Unified Method. in SIGCSE'04. 2004. Norfolk, Virginia: ACM Press.

4. McFall, R., et al. A Demonstration of a Collaborative Electronic Textbook Application on the Tablet PC. in World Conference on Educational Multimedia, Hypermedia and Telecommunications. 2004: AACE.

3. Mock, K., Teaching with Tablet PC's. Journal of Computer Science in Colleges, 2004. 20(2): p. 17 - 27.

5. Plimmer, B. and R. Amor. Peer Teaching Extends HCI Learning. in ITiCSE'06. 2006. Bologna, Italy: ACM Press.

6. Rodger, S.H. An interactive lecture approach to teaching computer science'. in Proceedings of the twenty-sixth SIGCSE technical symposium on Computer science education. 1995. Nashville.

4. Roth, W.M., et al., Differential participation during science conversations: The interaction of focal artefacts, social configurations, and physical arrangements'. Journal of the Learning Sciences, 1999. 8: p. 293 - 347.

7. Scheele, N., et al. Mobile Devices in Interactive Lectures'. in World Conference on Educational Multimedia Hypermedia and Telecommunications. 2004. Lugano.

8. Shneiderman, B., et al. Making a Difference: Integrating Socially Relevant Projects into HCI Teaching. in CHI 2006. 2006. Montreal, Canada: ACM Press.

9. Simon, B., et al. Preliminary Experiences with a Tablet PC Based System to Support Learning in Computer Science Courses. in ITiCSE'04. 2004. Leeds, UK: ACM Press.

10. Thomas, M., A. King, and T. Cetinguc. My First Year with a Tablet PC: Has Literacy Found a Means to Ubiquitous Computing at Last? in SITE. 2004: AACE. 